\title{
University students' propensity towards white-collar versus street crime
}

\begin{abstract}
Rochelle Watt
This study was conducted under the supervision of Professor Carolyn Yule, Sociology and Anthropology, College of Social and Applied Human Sciences, University of Guelph

While several traditional criminological theories have been used to explain the causes of white-collar crime, few research studies have examined the role that personality plays in explaining the causes of these types of crimes. University students were measured on two personality scales, self-control and desire for control, to determine the extent to which these factors affect the propensity to commit either street crime or white-collar crime. The findings indicate that self-control has the most significant effect on offending, but only when students indicated that they were willing to commit both street crime and white-collar crime. On the other hand, desire for control did not predict a propensity towards committing either type of crime.
\end{abstract}

$\mathrm{N}$ umerous traditional criminological theories have been used to explain white-collar crimes, which are defined as "violations of the law committed in the course of a legitimate occupation or financial pursuit of persons who hold respected positions in their communities" [1]. The theories that have been used in explaining these crimes include rational choice, neutralization, control, and differential association [2]. In general, offenders are found to be psychologically stable. Thus, it is believed that if they possess no psychological defects then there is no need to examine their personality factors to explain why they commit crimes. As a result, little theoretical work has been conducted to examine the effects of personality and an individual's traits on white-collar crime [2]. While there has been much speculation as to which personality factors may predispose someone to white-collar crime, there have been few recent studies actually testing any theories. Some theories that have been proposed describe white-collar criminals as being charismatic, in need of control, narcissistic, and as lacking integrity and a social conscience [3]. The question has been raised, but not completely answered, as to why successful, respected, and well-educated persons become involved in corporate and white-collar crimes. Why do these highly regarded individuals risk their reputations for the possibility of arrest and conviction?

Traditionally, public attention has focused on preventing violent crime, while white-collar crime was considered to be less damaging to society and individuals [3]. However, empirical evidence showing an increased willingness to endorse stiffer penalties and greater enforcement of penalties for white-collar crimes suggests that public attitudes are changing [3]. This growing concern speaks to the importance of focusing attention on whitecollar crime and which factors - specifically, which personality factors - cause individuals to commit these acts. Research by Weisburd, Wheeler, Wearing, and Bode suggest that white-collar criminals have no special personality traits, and argue that these individuals are just ordinary people who view illegal activity as the most reasonable way out of a difficult financial situation [4]. So, what is it then that actually causes white-collar criminals to commit the crimes they do? This present study will examine two personality factors, self-control and desire for control, to determine if they are related to university students' propensity to commit white-collar crime or street crime.

\section{White-Collar Crime}

The term 'white-collar crime' was first introduced by Edwin Sutherland in 1939, offering professionals a new understanding of the relationship between business and crime [3]. White-collar crime has been criticized for encompassing too much diverse and unrelated behaviour [1]. For example, there are organizational crimes that are committed with support from the organization with the goal of furthering its own ends, and then there are occupational crimes that are committed by individuals with the goal of personal gain [1]. Although white-collar activities cover a wide range of behaviours, Coleman believes that they share many similarities and should be treated as a single concept in research studies and analyses [1]. As stated previously, a white-collar offence occurs when a person of a high occupational status commits an illegal act in the course of his or her professional activity. The goal of a large majority of 
white-collar criminals is financial gain, or organizational success that may result in financial gain. In contrast, corporate crime is defined "as the conduct of a corporation, or of employees acting on behalf of a corporation, which is prescribed and punishable by the law" [2]. Consequently, since the principle of corporate crimes is specifically to advance corporate interests, while the principle of whitecollar crimes is for personal or organizational benefit, this present study will focus solely on white-collar crimes.

\section{SELF-CONTROL}

While motivation and other "traditional sociological processes" were seen as important causes of crime, including white-collar crime, Gottfredson and Hirschi renounce all of these theories [5]. Instead, the only explanation that Gottfredson and Hirschi proposed was a factor similar to greed (i.e., it is based on a person's desire to achieve shortterm pleasure and gain) [6] which derived from an internal characteristic of low self-control [5]. Low self-control is used to describe a stable criminal predisposition which increases the likelihood that individuals will be unable to resist the easy and immediate gratification that crime and other analogous behaviours (e.g. smoking, excessive drinking, fast driving, and gambling) provide [7]. In their general theory of crime, Gottfredson and Hirschi believe that early childhood socialization within the family produces low self-control [8]. Parents who are attached to their children will monitor, recognize, and punish inappropriate behaviour. As a result, these children will develop the self-control needed to resist easy gratification offered by misbehaviour. In contrast, weak direct controls exercised by parents will result in weak self-control in children [7].

Trait theories, in general, examine a combination of stable attributes that may explain criminality. Gottfredson and Hirschi's argument in regards to the cause of crime posits that low self-control is a stable, unidimentional trait consisting of six components. As such, the general theory of crime may be best described as a trait theory rather than a personality theory as traditionally defined in the field of psychology. The first component of their theory is impulsivity, which is described as responding to physical stimuli in the immediate environment and being unable to defer gratification. The second component - simple tasks describes an individual as avoiding complex tasks because they lack diligence and persistence; thus, they prefer easy and simple gratifications. Third, individuals with low selfcontrol are risk seekers who have a tendency to be adventurous rather than cautious. Fourth, the physical activity component suggests that individuals prefer physical activities rather than mental ones. Fifth, people with low selfcontrol are indifferent and insensitive to the feelings of others and are said to be self-centered. Finally, people with low self-control are characteristic as having a low tolerance, referred to as the temper component [8]. This overall description of self-control corresponds with Gottfredson and
Hirschi's view of crime as an activity that is "easy to commit, involves little planning, requires minimal physical skills, and provides immediate gratification" [7]. It is therefore not surprising that offenders tend to be impulsive, non-verbal, short-sighted, and so on. Although Gottfredson and Hirschi argue that low self-control increases criminality [6], crime will only occur if an opportunity to engage in such behaviour is present [7].

Several studies have empirically tested the general theory of crime and generally support the assertion that low self-control is significantly and positively related to crime and other analogous behaviours [9]. Even after controlling for measures of competing criminological theories, such as strain, social bond, differential association, and learning theories, low self-control has a significant effect on crime and deviance. In addition, low self-control is also "a significant predictor of negative life outcomes, including poor social bonds, lifestyles, and low socioeconomic attainment" [7].

In Gottfredson and Hirschi's general theory of crime, they contend that all crime, even white-collar crime, can be explained by the same underlying factors [5]. As a result, this general theory argues that white-collar offenders are just as resourceful and "prone to deviance as those who commit common street crimes" [5]. For Gottfredson and Hirschi, then, the same types of people commit both categories of offences. As such, labels such as a 'white-collar criminal' and a 'street criminal' are incorrect and misleading. If this view is correct, Benson and Moore argue that it has two implications. First, individuals who are labeled as whitecollar criminals will not specialize in white collar offences, but will instead commit a wide variety of spontaneous and impulsive crimes - similar to that of traditionally conceptualized street criminals. Second, criminals in general will participate in a number of deviant behaviours, such as engaging in drugs, promiscuous sex, and white-collar crimes [5].

If Gottfredson and Hirschi's proposition regarding the existence of only one type of offender is true, distinctions should be made between the types of offence committed rather than the offender [5]. Furthermore, Hirschi and Gottfredson believe that "when opportunity is taken into account, demographic differences in white-collar crime are the same as demographic differences in ordinary crime" [10]. The only clear difference that Gottfredson and Hirschi make between the two groups is that, by definition, white-collar offenders would be in the white-collar world and commit their crimes in that environment [11].

Alternatively, research conducted by Benson and Moore found that, on the whole, white-collar offenders can be clearly distinguished from street offenders [5]. In addition, research done by Wheeler, Weisburd, Bode, and Waring in 1988 that compared individuals convicted of white-collar crimes to individuals convicted of street crimes found that there are distinctions between these two groups [5]. More specifically, Wheeler, Weisburd, Bode, and Waring found 
that those convicted of white-collar crimes are more likely to have higher levels of education, to have had a history of steady employment, and to be older white males [5]. Piquero et al. contend that the general theory of crime and low selfcontrol cannot sufficiently explain white-collar crime [2].

Gottredson and Hirschi have themselves suggested that individuals with low self-control generally do not qualify for white-collar occupations, especially for positions with authority [2]. Instead, businesses favour individuals with "traits such as the ability to defer gratification and willingness to defer to the interests of others" [2]. Individuals with the personality characteristic of desire for control would most likely possess these traits, and therefore desire for control is believed to be related to corporate decision making [2].

\section{DESIRE FOR CONTROL}

Desire for control - the extent to which people prefer to control the events in their lives - has been examined with a wide range of psychological factors such as achievement, social interactions, conformity, and depression [12]. Individuals high in desire for control are believed to prefer making their own decisions, taking action to avoid losing control, and assuming leadership roles [13]. Furthermore, research conducted by Piquero et al. found that a desire for control was positively and significantly related to an intention to violate the law in order to maintain control over one's environment [2]. Specifically, those who possess high desire for control would be more likely to engage in corporate crimes to gain control over situations that are uncertain or appear irrational [2]. In other words, an individual's high level of desire for control influences their decision making process which is what ultimately relates desire for control to corporate offending. While some scholars argue that self-control conditions criminal behaviour (i.e. committing street crimes) [6], Piquero et al. contend that desire for control offers a better explanation for criminal behaviour in the white-collar world [2].

Although low self-control is more characteristic of offenders who commit street crime and a high desire for control is more characteristic of offenders who commit white-collar crime, this does not imply that offenders who engage in these two types of crime are complete opposites [2]. While the traits are distinct, they are also related and the presence of one does not necessarily require the absence of the other. The main distinction between low self-control and high desire for control is how offenders view the future individuals exhibiting a high desire for control are future oriented, while individuals exhibiting low self-control have a present-day orientation [2]. In addition, Burger proposes "that individuals high in the desire for control will display many of the behaviours that are related to higher achievement" [13]. This inclination towards higher achievement may speak to their future orientation, since high achievement often involves creating goals and aiming to achieve them at some point in the future. For example, a university degree may be considered a high achievement, which is why many individuals with a high desire for control hold more prominent jobs, and it is there that these whitecollar offences are committed.

\section{GENDER}

The motivation to commit white-collar crime is also different for men and women, with women more often motivated by relational goals including "a need to meet their responsibilities as wives or mothers" [11]. According to Daly, women are more likely to rationalize their crime on the basis of family need or maintaining relationships with a spouse. On the other hand, men tended to rationalize their crimes of embezzlement and fraud as 'borrowing' in order to resolve financial problems [11]. Overall, the number of female white-collar offenders is low relative to male whitecollar offenders. Some hypotheses that have been proposed to explain this gender gap are that the crimes committed by women result in pay-offs of lesser value, there is a lower likelihood of women working in organized crime groups, and men would rather not have women as crime partners [11]. Alternatively, it is also possible that women are in fact actively involved in white-collar offences but few are caught and prosecuted.

Another hypothesis that may explain this gender gap is that fewer women than men hold positions of power. While both men and women inhabit the white-collar world, men hold more managerial or professional positions while women hold more clerical roles [11]. As a result, men's crimes are both petty and major, while women are more often involved in petty crimes due to fewer opportunities. With common street crimes, except for a few exceptions such as prostitution, males are also more likely to offend than females [14].

Since a high level of desire control has been proposed to be related to white-collar offending, it should be noted that males occasionally score higher on the Desirability for Control Scale in comparison to females [12]. Conversely, some studies find no gender differences, and if a difference is examined, it has been suggested that this difference exists because of age [12]. For instance, middle-aged and older men consistently demonstrate a greater desire for control over their environment in comparison to women in those same age groups. A difference between male and female adolescents is rarely detected, and results are mixed for college undergraduate students [12].

\section{Post-SECONDARY EdUCATION}

It has often been assumed that higher education and a post-secondary degree will result in a better job and greater success in the work force. Research by Brown and Hesketh in 2004 demonstrated that graduate applicants for a fasttracked management program were from elite universities 
and middle-class backgrounds [15]. This suggests that a middle-class background and a university education may lead to more professional opportunities after graduation. There have been substantial changes in the labour market over the past 20 years which have increased employers' expectations regarding the need for a post-secondary degree for many jobs [15]. This may reflect the importance of postsecondary education in obtaining a job after one has graduated. Furthermore, Moreau and Leathwood contend that, overall, post-secondary graduates remain in a favourable position in comparison to non-graduates [15]. Despite the instability in the labour market, a majority of graduates continue to find their initial jobs in professional or professionally-related occupations [16]. Livingstone and Robertson believe that an undergraduate degree is the initial step toward professional development [16]. Therefore, there is an understanding that professional development may begin during one's undergraduate years [16]. It is believed, then, that university students are more likely to pursue professional jobs and enter the white-collar world after graduation. As a result, a sample specifically of university students was chosen for the current study.

\section{HYPOTHESES}

There are six hypotheses proposed for this study:

1. Since individuals with a high desire for control display behaviours related to higher achievement, this study hypothesizes that university students will be more inclined to commit white-collar crimes over street crimes. Since a university education may be considered higher education, higher achievement will most likely lead to a career in the white-collar world.

2. A) As a result of changing traditional gender roles and women striving to gain control over their lives, this study hypothesizes that there will be no significant difference in the desire for control measures for male and female university students - in agreement with previous research.

B) In regards to self-control, this study hypothesizes that males will score lower in comparison to females since males generally commit more street crimes and such deviance is traditionally characterized by a low measure of self-control.

3. A) Since males are more likely than females to commit street crimes, and since men's white-collar crimes are often considered more serious in comparison to women's whitecollar crimes, this study hypothesizes that male students, relative to female students, will have a greater inclination towards street crime and;

B) Male students, relative to female students, will have a greater inclination towards white-collar crimes.

4. Gottfredson and Hirschi argue that low self-control results in below average performance in everyday tasks; a failure in relationships and social institutions; job instability; the propensity to be attracted towards others who also have low self-control and are deviant; and the preference to gravitate towards the street [6]. Since many of these characteristics have been linked to criminal behaviour, this study hypothesizes that an individual who has a low measure of self-control will have a propensity towards committing street crimes.

\section{METHODS}

\section{Participants}

All of the participants that participated in this study are students at the University of Guelph. A survey was emailed to approximately 1280 students who were enrolled in at least one of SOC $1500 * 01$, SOC $1500 * 02$, SOC $2700 * 01$, SOC $2700 * 02$, SOAN $2120 * 01$, SOC $2070 * \mathrm{DE}$, and SOC $3490^{*} \mathrm{DE}$. It is likely that the total number of individual students who received an invitation to participate in this study is lower than 1280 , since some students were enrolled in more than one of the listed classes, and therefore, were counted twice. A total of 244 students answered the survey, of which, 186 completed it in its entirety. Only those 186 participants from whom complete information was obtained will be included in the analyses.

The participants were asked five questions about their demographics, including their gender, age, ethnicity, postgraduation plans, and whether they had ever received OSAP assistance (see Table 1 for frequency information for the demographic questions). Although the students were asked about their post-graduation plans and their use of OSAP assistance, these results were not used in the final analyses, and therefore, were not included in the demographics table.

\section{Materials}

There were no tangible materials used in this study since the survey used was made available online using SurveyMonkey. The Appendix contains the questions that were asked in the survey.

\section{Procedures}

Students enrolled in SOC $1500 * 01$, SOC $1500 * 02$, SOC $2700 * 01$, SOC $2700 * 02$, SOAN $2120 * 01$, SOC $2070 * \mathrm{DE}$, and SOC $3490 * \mathrm{DE}$ were sent an email inviting them to participate in this study. The link provided in the email brought them directly to the survey where they were presented with a participant consent form. The consent form provided information regarding the purpose of the study, the procedure, any potential risks and discomfort, compensation, confidentiality, and their right to withdraw. Once participants read and agreed to the outlines of the study, they continued onto the survey questions by clicking on the "Next" button. The survey consisted of demographic questions and three scales that assessed (1) the participant's measure of desire for control, (2) their measure of self-control, and (3) their attitudes toward certain types of crimes. The survey took approximately 15 to 30 minutes to complete and only required participants to participate once. At the end of the survey, the participants were thanked for their time and invited to contact the researchers or the University's 
Table 1. Demographic characteristics of the sample $(\mathrm{N}=186)$

\begin{tabular}{|c|c|c|}
\hline Characteristics & $\%$ & $\mathrm{n}$ \\
\hline \multicolumn{3}{|l|}{ Age } \\
\hline 18 & 21.5 & 40 \\
\hline 19 & 26.9 & 50 \\
\hline 20 & 18.3 & 34 \\
\hline 21 & 12.4 & 23 \\
\hline 22 & 4.8 & 9 \\
\hline 23 & 1.6 & 3 \\
\hline 24 & 3.2 & 6 \\
\hline 25 & 0.5 & 1 \\
\hline 27 & 1.1 & 2 \\
\hline 30 & 0.5 & 1 \\
\hline 40 & 0.5 & 1 \\
\hline 45 & 0.5 & 1 \\
\hline Did not answer & 8.1 & 15 \\
\hline \multicolumn{3}{|l|}{ Race/Ethnicity } \\
\hline White & 84.9 & 158 \\
\hline Non-White & 14.5 & 27 \\
\hline Did not answer & 0.5 & 1 \\
\hline \multicolumn{3}{|l|}{ Gender } \\
\hline Male & 19.4 & 36 \\
\hline Female & 80.6 & 150 \\
\hline Scales & $M$ & SD \\
\hline Self-Control & 2.1 & 0.7 \\
\hline Desire for Control & 4.9 & 2.0 \\
\hline
\end{tabular}

Counselling Services if they had any questions, comments, concerns, or emotional discomfort.

\section{RESULTS AND DISCUSSION}

\section{Independent Groups t-test}

Three Independent Groups t-tests were conducted to assess if there was a significant difference between the mean scale measures for male and female participants. The first $t-$ test examined if university students were more inclined towards committing white-collar crime or street crime. For this test, the likelihood of committing a crime for an individual who indicated that they would only commit a street crime $(M=1.23, S D=0.09)$ was slightly greater than the likelihood of committing a crime for an individual who indicated that they would only commit a white-collar offense $(M=1.21, S D=0.09)$. A Levene's test was conducted to determine if the variances of the two groups were homogenous and the results indicated that they were, $F(1$, $186)=1.23$, $n s$. Therefore, equal variance was assumed and the likelihood of both these groups to commit crimes was not found to be significantly different, with only a small difference $t(186)=0.76, n s, d=0.22$. Thus, university students are not more likely to commit one type of crime over the other.

The second Independent Groups t-test examined if there was a difference between what males and females scored on the desire for control scale. The mean desire for control score for females $(M=4.88, S D=0.62)$ was slightly greater than the mean desire for control score for males $(M=4.83, S D=$ 0.49 ). A Levene's test was conducted to determine if the variances of the two genders were homogenous and the results indicated that they were, $F(1,186)=2.73$, ns. Therefore, equal variance was assumed and the means for males and females were not found to be significantly different, with only a small difference between them $t(186)=$ $-0.34, n s, d=0.08$. Thus, males and females do not differ in terms of how much control they desire over the events in their environments.

The final t-test examined if there was a difference between what males and females score on the self-control scale. On this scale, the mean score for males $(M=2.12, S D$ $=0.29$ ) was slightly greater than the mean score for females $(M=2.10, S D=0.32)$. A Levene's test was conducted to determine if the variances of the two genders were homogenous and the results indicated that they were, $F(1$, $186)=0.40, n s$. Therefore, equal variance was assumed and the means for males and females were not found to be significantly different with only a small difference between them $t(186)=0.32, n s, d=0.07$. Thus, males and females do not differ in terms of how much they desire to obtain shortterm pleasure and gain.

\section{Multinomial Logistical Regression}

A Multinomial Logistical Regression was conducted to examine the relationship between gender, desire for control measures, self-control measures, and committing either street or white collar crime (while controlling for race and age). This analysis was used since the target variable of which type of crime university students are more likely to commit is a categorical variable (i.e. the levels are committing no crime, committing only street crime, committing only white-collar crime, and committing both crimes). Table 2 outlines how each variable was coded, and the results of this regression are provided in Table 3. The multinomial logistical regression compared students who said that they would not commit any type of crime to students who said that they would commit only a street crime, only a white-collar crime, and both types of crimes.

When controlling for age, desire for control, selfcontrol, and race, the results indicate that males are significantly more likely to commit only street crimes in comparison to females. There was no difference between male and female respondents in regards to white-collar crime or in regards to committing both types of crime.

When controlling for age, desire for control, gender, and race, the results also indicate that self-control was a significant predictor of committing white-collar crime only, as well as committing both white-collar and street crime. Therefore, unlike the results proposed by earlier research suggesting that low self-control predicts street crime [6], this study does not demonstrate that self-control predicts street crime unless the individual has positive attitudes toward committing white-collar crime as well. 
Table 2. Coding of variables

\begin{tabular}{lr}
\hline Variable name & Category \\
\hline Crime Type & \\
\hline No Crime & 1 \\
Street Crime Only & 1 \\
White-Collar Crime Only & 2 \\
Both Crimes & 3 \\
\hline Race/Ethnicity & 1 \\
\hline White & 2 \\
Non-White & 1 \\
\hline Gender & 2 \\
\hline Male & \\
Female & \\
\hline Scales & \\
\hline Self-Control & \\
Desire for Control & to 4 (strongly agree) \\
& 1 (statement does \\
& not apply) to 7 \\
& (statement always \\
& applies) \\
\hline
\end{tabular}

\section{Correlation}

A single Correlation was conducted to determine if there was a relationship between self-control and desire for control scores. A partial correlation was used to control for the age, race, and gender variables, and no significant relationship was found between self-control and desire for control, $r(165)=0.05, n s$.

\section{Conclusions}

The purpose of this study was to explore the extent to which various traits - specifically desire for control and selfcontrol - predict future offending in a sample of university students. Furthermore, these two traits, as well as an individual's gender, were used to determine whether a person would be more willing to commit a street crime or a whitecollar crime.

A majority of university graduates find their first jobs in professional or professionally-related occupations [16]. Therefore, it is believed that university students would enter white-collar environments after graduation, putting them in a position to commit these specific types of crimes. Despite being in this position, however, university students do not exhibit a propensity to commit white-collar crimes over street crimes. There was no difference found in this study between students who stated that they would only consider committing white-collar crimes and students who stated that they would only consider committing street crime. One explanation for these results is perhaps that a better measure of white-collar offending was needed. Since many of the students have probably not experienced the real-life pressures of working in a white-collar environment, the questions may not be relevant to them and they may have found it difficult to consider doing something to which they could not relate.

Burger and Solano argue that males, on occasion, score higher on the Desirability for Control Scale in comparison to females [12]. On the other hand, some research finds no gender differences in regards to desire for control, and results for college-aged individuals are mixed [12]. This study found that male and female university students do not differ on their desire for control scores (i.e. they both equally have a desire to control their environments and to have control in general terms). As proposed, changing gender roles may explain this finding. In the past, it was very difficult for women to gain access into an educational institution of higher learning [17]. In more recent years, women have accounted for the majority of students enrolled in university [18], demonstrating their desire to have control and power over their lives. Burger and Solano's research demonstrated that middle-aged and older men demonstrated a greater desire for control over their environment in comparison to women in those same age groups [12]. Such individuals may hold more conventional values and beliefs in which men have more power than women, while the younger generation contains males and females who believe they are equal to one another.

Similar to desire for control, there was also no difference found between male and female scores on the selfcontrol scale. One hypothesis of this study stated that males would have significantly lower scores on self-control (i.e. the inability to resist immediate gratification and gain) in comparison to females since males, in general, are more likely to commit street crimes [14]. However, low selfcontrol is also characteristic of other analogous behaviours such as smoking, excessive drinking, fast driving, and gambling - which females may be able to relate to rather than street crime. On the other hand, it could be argued that the males in this sample are just not inclined towards street crime and possess a fair amount of self-control. Therefore, their levels of self-control are equal to that of the females in the sample who also have a fair amount of self-control.

In general, university students might be expected to have high levels of self-control. Recall that one component of low self-control is simple tasks, which is defined as avoiding complex tasks because the individual lacks diligence and persistence; thus, they prefer easy and simple gratifications [6]. Attending university involves many academic challenges (i.e. tests, papers, exams, assignments, etc.), and students who graduate from their undergraduate programs (which represents a large majority of those enrolled) spend, at minimum, three years at a post-secondary institution. This dedication and hard-work perhaps represents why stronger evidence was not found for the effects of selfcontrol on offending. Since university students do not represent a high offending sample, it is not entirely surprising that self-control was not a significant personality 
Table 3. Multinomial logistical regression predicting crime offending preferences of university students

\begin{tabular}{|c|c|c|c|}
\hline $\begin{array}{l}\text { Type of } \\
\text { crime } \\
\text { committed }\end{array}$ & $B$ & SE $B$ & $e^{B}$ \\
\hline \multicolumn{4}{|c|}{ Street Crime Only } \\
\hline Age & .023 & .119 & 1.023 \\
\hline $\begin{array}{l}\text { Desire for } \\
\text { Control }\end{array}$ & .136 & .463 & 1.146 \\
\hline Self-control & -.160 & .909 & .852 \\
\hline Male & $1.297^{*}$ & .633 & 3.657 \\
\hline Non-white & .629 & .643 & 1.876 \\
\hline Intercept & -1.530 & 3.708 & \\
\hline \multicolumn{4}{|c|}{ White Collar Crime Only } \\
\hline Age & .176 & .098 & 1.193 \\
\hline $\begin{array}{l}\text { Desire for } \\
\text { Control }\end{array}$ & -.012 & .521 & .988 \\
\hline Self-control & $2.152^{*}$ & 1.019 & 8.600 \\
\hline Male & .420 & .756 & 1.522 \\
\hline Non-white & -.409 & .892 & .664 \\
\hline Intercept & $-8.633^{*}$ & 3.891 & \\
\hline \multicolumn{4}{|l|}{ Both Crimes } \\
\hline Age & -.001 & .103 & .999 \\
\hline $\begin{array}{l}\text { Desire for } \\
\text { Control }\end{array}$ & -.614 & .372 & .541 \\
\hline Self-control & $2.917^{\star \star *}$ & .765 & 18.484 \\
\hline Male & .164 & .589 & 1.179 \\
\hline Non-white & -.615 & .607 & .541 \\
\hline Intercept & -2.203 & 3.114 & \\
\hline
\end{tabular}

factor in students who stated that they would consider only committing either a street crime or a white-collar crime. In addition, even if an opportunity were present, individuals with low self-control, in general, are not certain to offend [19]. Therefore, it is very unlikely that the students in this sample who stated that they would consider only committing either a street crime or a white-collar crime would actually offend if an opportunity were present. Since their levels of self-control were not related to their likelihood of offending, this could be an example of how one's attitudes about offending do not match one's behaviour.

The lowest levels of self-control, which resulted in the most significant effect on offending, were found among the students who stated that they were willing to commit both street and white collar crimes. Since these students admitted that they would be willing to commit both types of crime, it is not surprising that they would exhibit the lowest levels of self-control in comparison to students who said that they would not commit any crime, to those who said that they would consider only committing street crime, and to those who said that they would consider only committing whitecollar crime.
Since it is widely agreed that males commit more street crime in comparison to females [14], it was not unexpected that the males in this study also exhibited a greater propensity towards committing street crime in comparison to females.

Regardless of the type of crime, desire for control does not predict whether a university student will consider committing a crime in the future. Desire for control scores were essentially the same for students who said that they would not commit either white-collar or street crime, for students who said that they would consider only committing street crime, who said that they would consider only committing white-collar crime, and those who said that they would consider committing both types of crime. These results are in contrast to research conducted by Piquero et al. who found that the desire for control personality characteristic was positively and significantly related to violation intentions [2]. Even after controlling for a number of scenarios and individual characteristics, Piquero et al. found that persons who rank high in desire for control may actually engage in corporate crimes as a mean of controlling their environments [2]. One explanation for the difference between Piquero et al.'s study and this present study may be the dependent variable used. The levels of the dependent variable used in this study were committing no crime, committing only street crime, committing only white-collar crime, and committing both crimes. Recall that white-collar crimes are committed by a single individual for personal financial gain. In contrast, Piquero et al. focused specifically on corporate crime, in which the company or organization benefits directly from the crime [2]. Therefore, the difference between these studies lies in terms of who benefits directly from the criminal act. It could be argued that desire for control only has an effect on corporate offending in which the company benefits, but does not have an effect on whitecollar offending in which only the individual benefits.

Furthermore, another possible explanation as to why the results of these two studies differ is that the sample of university students used in this present study had, overall, lower levels of desire for control in comparison to Piquero et al.'s sample. The desire for control scale mean for this study was 97.47 with a standard deviation of 11.62 , while the average in Piquero et al.'s study was 107.92 with a standard deviation of 9.52. This difference may indicate that the students in this study do have a lower level of desire for control, and therefore, would not be inclined to commit crimes due to this personality factor. Future research studies should examine if this difference is significant, and at what point a desire for control score becomes significant in predicting white-collar offending behaviour.

\section{Limitations}

One limitation of this study was the sample that was used. The sample used consisted entirely of university students; therefore, results obtained from this study cannot be generalized to the broader population. Furthermore, 
university students are not a high offending group, so it is not surprising that there was not stronger evidence that this group would be willing to commit crime. A university population is special in that their status as a post-secondary student demonstrates that they are more likely to be motivated, future-oriented individuals who possess high selfcontrol. Future research studies should attempt to use a more varied sample, possibly controlling for education. While this study specifically aimed to examine the effects of selfcontrol and desire for control on offending for university students, a general test involving participants of various education levels to examine whether self-control and desire for control drives offending is an important avenue for future investigation. Such a study could use participants in high school, college, university, trade school, and graduate school to determine if education level affects one's level of selfcontrol and desire for control - as well as one's propensity towards committing white-collar or street crime.

Another limitation of this study was the sample size. Perhaps greater effects would have been discovered if the sample was larger. For example, among the students who said that they would consider only committing a white-collar crime, the effect of age was close to being significant at 0.072. Perhaps if more participants were used, a greater effect may have been revealed. In addition, this study was limited in that over 80 percent of the 186 participants were female, which may have had implications when comparing the results for males and females.

Final limitations of this study were the crime questions that were used. Although the six crime questions were pretested before being administered in the survey, perhaps more preliminary analyses would have been useful to determine if the questions were an accurate gauge of a student's propensity to offend in the future. The vignettes were excluded from final analyses due to their lack of predicting any offending behaviours in this sample. Since the vignettes were created to be more realistic of situations in which students would find themselves, it could be argued that the students responded to these questions in a socially desirable manner to refrain from appearing criminally minded (both to the researcher and to themselves). Therefore, future research should pay great attention to the questions used in determining a dependent variable measure.

\section{REFERENCES}

1. Coleman, J.W. (1987). Toward an integrated theory of white-collar crime. The American Journal of Sociology, 93(2), 406-439, pg. 407.

2. Piquero, N.L., Exum, M.L., \& Simpson, S.S. (2005). Integrating the desire-for-control and rational choice in a corporate crime context. Justice Quarterly, 22(2), 252280, pg. 256.

3. Price, M., \& Norris, D.M. (2009). White-collar crime: Corporate and securities and commodities fraud. The
Journal of the American Academy of Psychiatry and Law, 37, 538-544.

4. Weisburd, D., Wheeler, S., Waring, E., \& Bode, N., (1991). Crimes of the middle classes: White-collar offenders in the federal courts. New Haven, CT: Yale University Press.

5. Benson, M.L., \& Moore, E. (1992). Are white-collar and common offenders the same? an empirical and theoretical critique of a recently proposed general theory of crime. Journal of Research in Crime and Delinquency, 29(3), 251-272, pg. 252.

6. Gottfredson, M.R., \& Hirschi, T. (1990). A general theory of crime. Stanford, CA: Stanford University Press.

7. Pratt, T.C., \& Cullen, F.T. (2000). The empirical status of Gottfredson and Hirschi's general theory of crime: A meta-analysis. Criminology, 38(3), 931-964, pg. 932, 934.

8. Grasmick, H.G., Tittle, C.R., Bursik, R.J., \& Arneklev, B.J. (1993). Testing the core empirical implications of gottfredson and hirschi's general theory of crime. Journal of Research in Crime and Delinquency, 30(1), 5-29.

9. Baron, S.W. (2003). Self-control, social consequences, and criminal behavior: street youth and the general theory of crime. Journal of Research in Crime and Delinquency, 40(4), 403-425.

10. Hirschi, T., \& Gottfredson, M. (1989). The significance of white-collar crime for a general theory of crime. Criminology, 27(2), 359-371, pg. 364.

11. Daly, K. (1989). Gender and varieties of white-collar crime. Criminology, 27(4), 769-794, pg. 771.

12. Burger, J.M., \& Solano, C.H. (1994). Changes in desire for control over time: gender. Sex Roles, 31(7), 465-472.

13. Burger, J.M. (1985). Desire for control and achievementrelated behaviors. Journal of Personality and Social Psychology, 48(6), 1520-1533, pg. 1521.

14. Bernard, T.J., Snipes, J.B., \& Gerould, A.L. (2010). Vold's theoretical criminoloy. New York, New York: Oxford University Press, Inc.

15. Moreau, M.P., \& Leathwood, C. (2006). Graduates' employment and the discourse of employability: A critical analysis. Journal of Education and Work, 19(4), 305-324.

16. Holden, R., \& Harte, V. (2003). New graduate engagement with "professional development". Journal of European Industrial, 28(2), 272-282.

17. Jacobs, J.A. (1996). Gender inequality and higher education. Annual Review of Sociology, 22, 153-185.

18. Statistics Canada, Tourism and the Centre for Education Statistics Division. (2011). Education indicators in Canada (Catalogue no. 81-599-X - Issue no. 006). Ottawa, ON: Main Building.

19. Muraven, M., Pogarski, G., \& Shmueli, D. (2006). Selfcontrol depletion and the general theory of crime. Journal of Quantitative Criminology, 22, 263-277 